Table 2

Mean Number of Tokens Earned and Donated to the Model as a Function of Treatment and Age

\begin{tabular}{|c|c|c|c|c|c|c|}
\hline \multirow[b]{3}{*}{ Treatment } & \multicolumn{6}{|c|}{ Age } \\
\hline & \multicolumn{2}{|c|}{$6-8$} & \multicolumn{2}{|c|}{$9-11$} & \multicolumn{2}{|c|}{ Combined } \\
\hline & Earned & Donated & Earned & Donated & Earned & Donated \\
\hline $\begin{array}{l}\text { "Neutral" Model } \\
\text { "Friendless" Model }\end{array}$ & $\begin{array}{l}11.67 \\
11.67 \\
\end{array}$ & $\begin{array}{l}1.33 \\
6.33\end{array}$ & $\begin{array}{l}11.67 \\
11.50\end{array}$ & $\begin{array}{l}1.50 \\
3.33\end{array}$ & $\begin{array}{l}11.67 \\
11.58\end{array}$ & $\begin{array}{c}1.41 \\
4.83\end{array}$ \\
\hline
\end{tabular}

Imitation of the Modeled Choices

To the degree that Ss' preferences were influenced by observation of $M$, their own choices should correspond with his more often after exposure to the film than before. As seen in Table 1, this modeling effect was obtained. Moreover, a 3 by 2 by 2 analysis of variance of similarity scores, with sessions as a repeated measure, revealed a significant difference in similarity scores between the sessions $(F=11.02, p<.005)$ and no other significant effects. Both the "neutral" model and "friendless" model groups increased in their similarity to $M$ after watching $\operatorname{him}(\mathrm{t}=2.21$ and $2.97, \mathrm{p}<.05$ and $<.01$, respectively, two-tailed), whereas the no-model control group did not change significantly on this measure $(t=.48)$.

Reproduction of

the Modeled Choices

Table 2 presents the mean number of tokens earned for reproduction of M's choices in all film groups. These data suggest that almost perfect acquisition and retention of M's choices was engendered by the single 4-min exposure. A 2 by 2 analy sis of variance on these scores revealed no significant differences as a function of modeling group, age, or the interaction of these variables.

\section{Prosocial Behavior}

Toward the Model

Table 2 also presents the mean number of tokens donated to $M$ according to film group and age of Ss. A 2 by 2 analysis of variance performed on these scores supports the hypothesis that ascribed "friendlessness" significantly enhances prosocial behavior $(\mathrm{F}=8.46, \mathrm{p}<.01)$. There was no significant effect for age $(F=1.46)$ on this measure, and the Age by Treatment interaction was not significant $(F=1.82)$.

\section{DISCUSSION}

As in recent studies of prosocial behavior (Hornstein, Fisch, \& Holmes, 1968), the present investigation was concerned with the contribution of social factors to symbolic modeling cues. Thus, all experimontal Ss were told that other children had made contributions to $M$. The results presented in Table 2 suggest that the combination of such symbolic modeling and a friendless recipient may be a very potent combination for inducing altruistic behavior. In fact, on the average, children exposed to these influences donated more than $40 \%$ of the tokens they had earned to their friendless filmed peer.

Despite a clear modeling effect, results failed to support the "sympathy" hypothesis that a friendless $M$ enhances imitation. Moreover, two plausible alternative reactions to a friendless $\mathrm{M}$, nonimitation and counterimitation (i.e., no preference changes and preference changes away from M's, respectively) also failed to obtain. Instead, children in both filmed groups showed significant and approximately equal levels of imitation. Recall that $M$ apparently had the opportunity to examine these items first-hand, whereas the Ss themselves were provided with only pictorial representations. If the children assumed that first-hand inspection permits a more adequate evaluation, then the difference in mode of presentation of the items for $M$ and $S$ might have enhanced the information value of the modeling cues, outweighed the potential influence of "friendlessness," and produced the uniform modeling effect.

Of special interest is the nearly perfect matching scores of all groups under high incentive conditions (Table 2). The design used required all $S s$ to first choose between commodities from pairs of nearly equal value and then afforded them the opportunity to observe the choices of another child in a similar situation. It is plausible that this sequence engenders an unusually high level of interest and attention, a tentative interpretation supported by the observation that many children not only appeared to be attending avidly to the film but also spontaneously clapped their hands or "booed" as M's choices matched or deviated from their own earlier ones.

\section{REFERENCES}

BANDURA, A. Influence of models' reinforcement contingencies on the acquisition of imitative responses. Journal of Personality \& Social Psychology, 1965, 1, 589-595.

HORNSTEIN, H. A., FISCH, E., \& HOLMES, M. Influence of a model's feeling about his beh avior and his relevance as a comparison other on observers' helping behavior. Journal of Personality \& Social Psychology, 1968, 10, 222-226.

MURPHY, L. B. Social behavior and child personality. New York: Columbia University Press, 1937.

\section{NOTE}

1. This study was supported, in part, by National Institute of Child Health and Human Development Grant No. HD 03573 and National Science Foundation Grant No. GY 3054 for undergraduate research. Grateful acknowledgement is due to the East Nashville Y.M.C.A. for permitting us to conduct the study and to the Eastman-Kodak Company for loan of a sound projector.

\title{
Memory loci in artificial memory
}

\section{HERBERT F. CROVITZ, Veterans Admin- istration Hospital, Durham, N.C. 27705}

Recent studies have begun to evaluate the ancient art of artificial memory in which first a set of places is memorized, and later things or words to be memorized are "put in those places with bizarre images. "Students of the ancient art of memory spent much effort in selecting places. However, 12 students learned 34 of 40 words in their correct sequence in one trial, using for places an arbitrary map of a street. Self-produced memory-maps are thus not a necessary part of the artificial memory process.

Yates (1966) interprets much of intellectual history from the time of Simonides to the time of Leibniz in terms of the classical art of artificial memory. The art of first memorizing a set of places, and then memorizing things or words by placing them at those locations with bizarre images had been mostly lost and is very recently becoming a topic for experimental analysis. Galton (1879) presumably did not know that he imitated the classical memory walk on his famous halting stroll down Pall Mall, and Luria $(1960,1968)$ treated the memory walks of Shereskevskii along Gorky Street as mysterious, awesome, and demonstrative of a peculiar memory talent.

The first step in classical artificial memory is the storing in memory of a series of places. Ross \& Lawrence (1968) recently tested the feasibility of a walk in which memory places could be chosen and memorized. They reported that 52 places on the campus of the University of Western Australia were memorized in two walks. 
After the places were memorized, a list of 50 words was read once to $S$ who transformed them into bizarre images at the already memorized places, and then could retrieve the words in order without error.

Analysis of classical artificial memory is needed to find the necessary parts of it. The present study asks whether $S$ must first select and memorize a set of memory-places in order that a long list can then be learned on a single trial by "putting bizarre images at places."

\section{METHOD}

A set of 20 fictitious locations along an artificial "map of Gorky Street" was drawn on a classroom blackboard. The 20 successive locations were labeled: ELECTRIC COMPANY, GAS STATION, OCULIST, PERSIAN RUGS, FLORIST, LOANS, BUS TERMINAL, PLUMBER, JAIL, NEWSPAPER STAND, SIDEWALK CAFE, USED CARS, NURSERY, DRY CLEANER, GUNS, PHONE BOOTH, DAIRY, PET STORE, MOTEL, BOOK SHOP. These specific locations were suggested by a haphazard search in the Yellow Pages of the Durham telephone book, though no known street has these successive locations.

A set of 40 words was selected. They were: crush, umbrella, sailor, cedar, mischief, salute, school, bashful, ride, clean, dark, prospect, allow, captain, gift, path, grocery, satisfy, occasion, perverse, nuisance, master, sulphur, preach, minnow, invite, soldier, cabbage, escape, irksome, true, steep, riot, raisin, promise, apricot, stone, doll, overcoat, eagle (from Woodworth, 1938, p. 10).

Subjects were 12 undergraduates, tested in a group. They were instructed: "I am going to read a list of words. I want you to picture them vividly at the 20 successive locations along this map of Gorky Street. There will be 40 words so on the second time around you will have to put a second item in each location. Try to make bizarre images connecting the locations with the words."

The 40 words were read aloud by $E$ with about $8 \mathrm{sec}$ between successive words. After the last word was read, $\mathrm{S}$ was instructed to number a sheet of paper 140 and write down the words in the order they had been presented. About $60 \mathrm{sec}$ separated the end of E's reading and the start of S's writing.

RESULTS AND DISCUSSION

Among the 12 Ss the mean number of words written in the correct place in the sequence was 34.25 . Two Ss missed 19 and 29 words, respectively. The former afterwards reported that on the first "walk along Gorky Street" he had not made bizarre images, but had instead pictured himself standing in the middle of Gorky Street "throwing the words into the shops." The latter $S$ reported she was trying to rehearse the words to herself and did not have time to make bizarre images as well.

The practical trouble with the classical artificial memory system is the need to commit a sequence of places to memory first: making bizarre images was taken to be rather easy and retrieval to be effortless. With this arbitrary drawn-out map of Gorky Street, most entirely unpracticed Ss also found that making bizarre images was rather easy and indeed retrieval was effortless, and very enjoyable. However, the practical trouble with an imaginary walk along a drawn-out map is that retrieval does depend on having the map to consult. With the map on the blackboard most Ss correctly wrote that the 36th word was apricot when the map was available to lead to the 36th location (PHONE BOOTH on the second walk along Gorky Street). Without the map there is no easy way to get to the PHONE BOOTH and thence to the apricot.

The theoretical point that these data suggest is that the classical art of artificial memory does not depend upon $\mathrm{S}$ by his own efforts first committing a set of memoryplaces to memory; an arbitrary list of places given to him without his effort also works fairly well.

An educational advantage of the willing. ness of memory to use arbitrary memory. places is that a walk along Gorky Street can be used as a classroom demonstration of artificial memory. Schiffman ${ }^{1}$ drew a 50-location "map of Gorky Street" on a blackboard for a class in introductory psychology, with 80 students in the room. He then read off 50 things to be remembered at the 50 successive locations, and at the end pointed to various places and the class said aloud the words he had read at that place in the list represented by that location. The session is said to have led to active participation and successful retrieval on the part of most students.

In the present study the two Ss who did poorly did not always "put bizarre images" at the successive locations. Delin (1968) made a special study of the effect of bizarreness of the image that Ss made to connect paired associates who were told to connect the words vividly. Judges rated the vividness of the image that Ss reported; 15 weeks later Ss were tested on the paired-associate list. Success at memory retrieval was positively related to the judged vividness of the previously reported images. Wallace, Turner, \& Perkins (1960) had reported a seminal study related to these matters before Yates (1966) was available. Their study consisted of reading hundreds of pairs of words to $S$ with instructions to make a bizarre image connecting them. Then when one word of a pair was given, $S$ usually could produce the second word of the pair. In a recent book, Bartz (1968) concludes that such memory feats are not limited to individuals with some sort of "memorytalent," but that "anyone with ambition could do the same."

Among the remaining theoretical questions is the question of precisely what it is that $S$ must do. For Ss with perfect performance in the present study, the "bizarre images" included "sitting on a light bulb" (for crush at ELECTRIC COMPANY), "a geyser erupting from a gasoline tank" (for umbrella at GAS STATION), and "Popeye squinting at an eye chart" (for sailor at OCULIST). Bugelski, Kidd, \& Segmen (1968) had Ss memorize a list of 10 common nouns using a rhyming mnemonic (one is a bun; two is a shoe; etc.) with 2,4 , or $8 \mathrm{sec}$ between successive items. The $2 \cdot \mathrm{sec}$ rate was too fast for perfect performance, perhaps because it was too fast for "making images." The authors question the appropriate level of analysis of what $S$ must do, granting as competitors "some verbalization, some sentence formation, story construction or bizarre association." The use of arbitrary memory maps like the present Gorky Street makes the classical memory technique rather more accessible, for $S$ need not first roam through empty buildings and along deserted streets in classic preparatory attempts to commit memory places to "normal memory" so that "artificial memory" may begin. The methodological value of making the "artificial memory" more accessible may be that it may facilitate studies designed to tease out what precisely $S$ must do as he "makes bizarre images."

\section{REFERENCES}

BARTZ, W. H. Memory. Dubuque: Brown, 1968. BUGELSKI, B. R., KIDD, E., \& SEGMON, J. Image as a mediator on one-trial paired-associate learning. Journal of Experimental Psychology, $1968,76,69-73$.

DELIN, P. S. Success in recall as a function of success in implementation of mnemonic instructions. Psychonomic Science, 1968, 12, 153-154.

GALTON, F. Psychometric experiments. Brain, $1879,2,149-157$.

LURIA, A. R. Memory and the structure of mental processes. Problems of Psychology, 1960, 4, 81-94.

LURIA, A. R. The mind of a mnemonist. New York: Basic Books, 1968.

ROSS, J., \& LAWRENCE, K. A. Some observations on memory artifice. Psychonomic Science, 1968, 13, 107-108.

WALLACE, W. H., TURNER, S. H., \& PERKINS, C. G. Preliminary studies of human information storage. In G. A. Miller, E. Galanter, and K. H. Pribram (Eds.), Plans and the structure of behavior. New York: Rinehart \& Winston, 1960.

WOODWORTH, R. S. Experimental psychology. New York: Holt, 1938.

YATES, F. A. The art of memory. Chicago: University of Chicago Press, 1966. NOTE

1. Schiffman, Harold. Personal communication, 1968. 